\title{
The Study of Teachers' Attitudes of Positive Disciplines and Class Management Effectiveness in Junior High School
}

\author{
Chia-Ling Shih, Chin-Chang Wu, Fang-Pin Lai, and Chin-Wen Liao
}

\begin{abstract}
This study is aimed to discuss the difference that teachers come from various backgrounds and school environments whose attitudes of positive disciplines and class management effectiveness.

The sampling target is full- time teachers at public junior high schools in central area of Taiwan who taught from September 1, 2012 to August 31, 2013.

The study gives out 760 questionnaires which are 618 usable and the return rate of usable questionnaires is $81.3 \%$.

The collected data are analyzed by using frequency distribution, percentage, mean, standard deviation, t-test, one-way ANOVA, Scheff's method and Pearson's production-moment correlation.

According to the result of this study, the conclusions are summarized as follow: 1) Teachers in junior high school who have master or doctoral degree and ages are 41 to 50 have better attitude of positive discipline. 2) Teachers in junior high school are under 30, both in teaching and administrative positions, less than five years seniorities, and have master or doctoral degree who have better class management effectiveness. 3) Teachers teach in remote junior high schools that students less 100 have better attitude of positive discipline and class management effectiveness. 4) Teachers' better attitude of positive discipline significant impact class management effectiveness.
\end{abstract}

Index Terms-Teachers in junior high school, attitude of positive discipline, class management effectiveness.

\section{INTRODUCTION}

\section{A. Introduction}

After the Legislative Yuan of Republic of China voted through legislation of prohibiting punishment, the Ministry of Education set the regulation of "The Precaution for School to Set the Note of Teacher Counsels and Disciplines Student (MOE, 2007) [1]'. MOE is committed creating a friendly campus, and in order to "protect student's right, maintain the dignity of teacher" as the goal for years. Right now, the positive discipline is the main way of schooling. No punishment in campus and positive discipline are the trend and has been pushing in six years. Understanding teachers' attitudes and perceptions of positive discipline who do teach in school, it is the one of motivations for the study.

Otherwise, junior high school teachers keep attitudes and do the way of positive discipline really significant impact

Manuscript received April 8, 2014; revised June 16, 2014. This work was supported in part by the Ministry of Science and Technology under Grants NSC 102-2511-S-018 -010.

The authors are with the Department of Industrial Education and Technology, National Changhua University of Education (NCUE), Taiwan (e-mail: malisa168@yahoo.com.tw, wcc1102@yahoo.com.tw, lion0829@gmail.com, tcwliao@cc.ncue.edu.tw). class management effectiveness. To understand the effectiveness how junior high school teachers put into effect positive discipline, we work out to study "teachers in junior high school whose attitudes of positive disciplines and class management effectiveness." It is the second motivation.

Third, the study centers on junior high school teachers who teach in area of central Taiwan. Going through literatures on this study, there are many studies in attitudes of positive discipline and class management effectiveness; studying in elementary school teachers' positive discipline and class management effectiveness are Zhou (2009) [2], Lai (2010) [3] and Ye (2011) [4]; One of studies in class management effectiveness to be related positive discipline of junior high school mentors in Taoyuan county is Lu (2011) [5]; Zheng (2011) [6] studies in the relations between positive discipline, class ambience and class management effectiveness of junior high school mentors in Hsinchu area; Liu and Lin (2007) [7] studies in class management effectiveness to be bound up with positive discipline in junior high school mentors at Kaohsiung city. No recent data studies in junior high school teachers' positive disciplines and class management effectiveness in central Area of Taiwan, so it is why this study targets on junior high school teachers in central Taiwan.

\section{B. Purpose}

According to the above motivations, purposes of this study are as follows:

1) To study the difference that junior high school teachers come from various background variables whose attitudes of positive discipline.

2) To study the difference that junior high school teachers come from various background variables whose class management effectiveness.

3) To analyze the relation between teachers' attitudes of positive discipline and class management effectiveness.

\section{Methodology}

\section{A. Methods and Procedures}

To achieve the goal, methods and procedures of this study are as follows:

1) Methods: The research tool is self- designed questionnaire. The conclusions and recommendations are based on the analysis of survey.

2) Procedures: show as in Fig. 1.

\section{B. The Study Framework}

The frameworks of this study are a) independent variable 
of teacher background, b) independent variable of school environment, c) dependent variable of teachers' attitudes of positive discipline and d) dependent variable of class management effectiveness.

One of independent variables is teacher background variables which include gender, age, educational level, teaching seniority and position. The other is school environment variables which include constructions, locations and number of students of school.

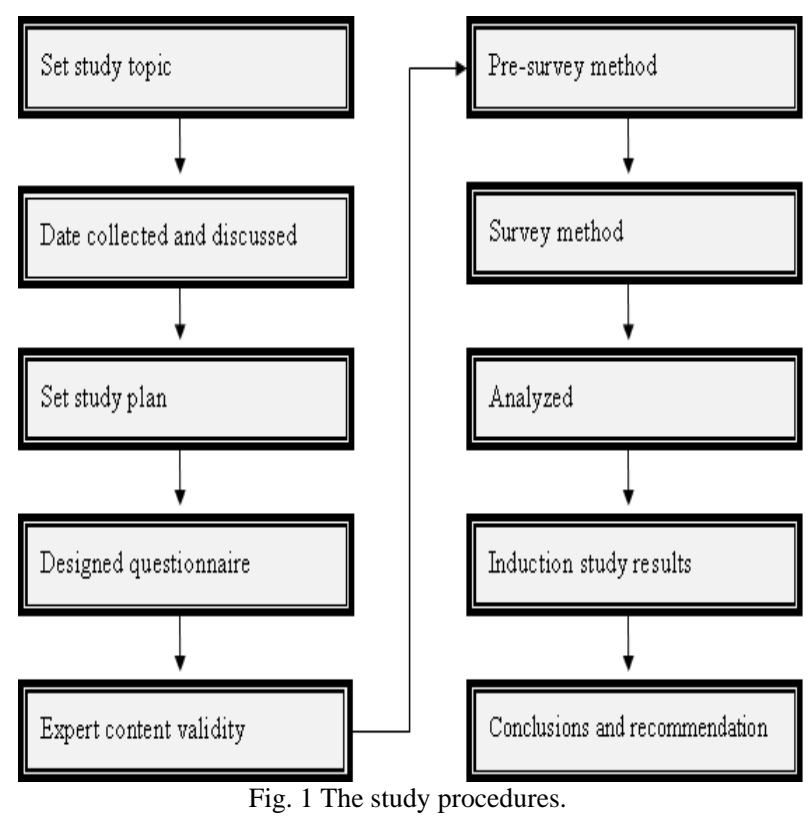

There are two dependent variables. One is teachers' attitudes of positive discipline which contains four aspects those are right perception, emotional management, discipline and supporting system. The other is class management effectiveness which contains six aspects those are teaching quality, learning effect, teaching environment, student's performance, class ambience and interaction among teacher and student.

\section{The Study Population and Sample}

The study population is 10,101 people who are teachers on regular staff in public junior high school at Taiwan academic year of 2012 in central Taiwan which include Taichung City, Changhua County, Nantou County. The target does not contain teachers of complete school and private school.

1) Pre- survey: Based on constructions and proportion to city and county of school, the pre- survey sends out 160 questionnaires and 144 of them are usable from Mar. 1 to 20, 2013.

2) Survey: In order to reduce errors in this study, the survey must be rigorous and reasonable to infer to the population. The survey sends out 760 questionnaires in Taichung City, Changhua County and Nantou County, and 618 of them are usable.

\section{The Study Tools}

The questionnaire has three parts. First is "basic information" which contains gender, age, educational level, teaching seniority, position, school's constructions, school's location and numbers of student. Second is "junior high school teachers' attitudes of positive discipline"; third is "junior high school teachers in class management effectiveness". According to the study purposes and collected date, it compiles the questionnaire named "The Study of Teachers in Junior High School Whose Attitudes of Positive Disciplines and Class Management Effectiveness in Central Area of Taiwan" as a tool.

\section{E. A Reasonable Questionnaire}

After the adviser reads and revises the draft of questionnaire, this draft reedit to the proper title and words by the suggestions from experts and vocational representatives of Electrical and Electronics group that could be more reasonable for presurvey.

\section{F. Presurvey and Analysis}

The pre- survey carries on the questionnaire is revised. To select the target is the first step of stratified sampling. To divide junior high schools stand on its numbers of student into four types which are class numbers under 12, among 13 24, among 25 48 and over 49. To arrange the numbers of questionnaire for each school is according to the percentage of each type is calculated. The second step is purposive sampling. According to students number and the percentage in city and county of school from the population, there are 11 schools are picked. The pre-survey send out 160 questionnaires and 144 of them are usable from Mar. 1 to 20, 2013. In order to obtain a more rigorous and reliability research tool, it uses SPSS statistic to analyze the item analysis and factor analysis; to verify the Cronbach's $\alpha$. In this scale, the Cronbach's $\alpha$ coefficient is over 90 which means the questionnaire expresses a high scale and can be the formal questionnaire.

\section{G. Formal Questionnaire}

The questionnaire is improved by experts' recommendations, and analyzed by item analysis, factor analysis and reliability analysis. After deleting inappropriate subjects, it compiles into a formal questionnaire.

\section{DATA ANALYSIS}

According to the data of questionnaire which named "The Study of Teachers in Junior High School Whose Attitudes of Positive Disciplines and Class Management Effectiveness in Central Area of Taiwan", it aims at questions to be answered and hypotheses to analyze and discuss.

\section{A. To Analyze the Difference That Junior High School Teachers Come from Various Background Variables Whose Attitudes of Positive Discipline}

The analysis of 3.1 is in the following Table I.

According to results of Table I, the background variables of Educational level and Constructions of school are significant differences in supporting system, discipline, emotional management and positive discipline.

\section{B. To Analyze the Difference That Junior High School Teachers Come from Various Background Variables Whose Class Management Effectiveness}

The analysis of 3.1 is in the following Table II.

According to results of Table II, the background variable of gender is no significant differences in each aspect. But the age is significant differences in every aspect. 
TABLE I: THE ANALYSIS OF DifFERENT BACKGROUND VARIABLES OF VIEWS ON ATTITUDE OF POSITIVE DisCIPLINE

background variables/assumed

Gender/ H01-1

Age/ H01-2

Educational level /H01-3

Teaching seniority /H01-4

Position /H01-5

Constructions of school

/H02-1

Location of school/ H02-2

Students number/ H02-3

\begin{tabular}{|c|c|c|}
\hline \multirow{2}{*}{ aspect } & \multicolumn{2}{|l|}{ results } \\
\hline & Significant differences & No significant difference \\
\hline Supporting system & & $*$ \\
\hline right perception & & $*$ \\
\hline discipline & & * \\
\hline emotional management & & * \\
\hline positive discipline & & * \\
\hline Supporting system & & * \\
\hline right perception & * & \\
\hline discipline & & * \\
\hline emotional management & & * \\
\hline positive discipline & * & \\
\hline Supporting system & * & \\
\hline right perception & & * \\
\hline discipline & * & \\
\hline emotional management & * & \\
\hline positive discipline & * & \\
\hline Supporting system & & * \\
\hline right perception & & * \\
\hline discipline & & * \\
\hline emotional management & & * \\
\hline positive discipline & & * \\
\hline Supporting system & & * \\
\hline right perception & & * \\
\hline discipline & & * \\
\hline emotional management & * & \\
\hline positive discipline & & * \\
\hline Supporting system & * & \\
\hline right perception & & * \\
\hline discipline & * & \\
\hline emotional management & * & \\
\hline positive discipline & * & \\
\hline Supporting system & & * \\
\hline right perception & * & \\
\hline discipline & & * \\
\hline emotional management & & $*$ \\
\hline positive discipline & & $*$ \\
\hline Supporting system & & * \\
\hline right perception & & $*$ \\
\hline discipline & $*$ & \\
\hline emotional management & $*$ & \\
\hline positive discipline & & * \\
\hline
\end{tabular}

TABLE II: THE ANALYSIS OF DIFFERENT BACKGROUND VARIABLES OF VIEWS ON CLASS MANAGEMENT EFFECTIVENESS

\begin{tabular}{|c|c|c|c|}
\hline \multirow{2}{*}{ background variables/assumed } & \multirow{2}{*}{ aspect } & \multicolumn{2}{|l|}{ results } \\
\hline & & Significant differences & No significant difference \\
\hline \multirow{7}{*}{ Gender/ H03-1 } & learning effect & & $*$ \\
\hline & classroom ambience & & $*$ \\
\hline & teaching environment & & $*$ \\
\hline & student's performance & & $*$ \\
\hline & interaction among teacher and student & & $*$ \\
\hline & teaching quality & & $*$ \\
\hline & classroom management & & $*$ \\
\hline \multirow{7}{*}{ Age/ H03-2 } & learning effect & $*$ & \\
\hline & classroom ambience & $*$ & \\
\hline & teaching environment & $*$ & \\
\hline & student's performance & $*$ & \\
\hline & interaction among teacher and student & $*$ & \\
\hline & teaching quality & $*$ & \\
\hline & classroom management & $*$ & \\
\hline \multirow{7}{*}{ educational level /H03-3 } & learning effect & $*$ & \\
\hline & classroom ambience & & $*$ \\
\hline & teaching environment & & $*$ \\
\hline & student's performance & & $*$ \\
\hline & interaction among teacher and student & $*$ & \\
\hline & teaching quality & $*$ & \\
\hline & classroom management & $*$ & \\
\hline \multirow{4}{*}{ teaching seniority/ H03-4 } & learning effect & $*$ & \\
\hline & classroom ambience & & $*$ \\
\hline & teaching environment & $*$ & \\
\hline & student's performance & $*$ & \\
\hline
\end{tabular}




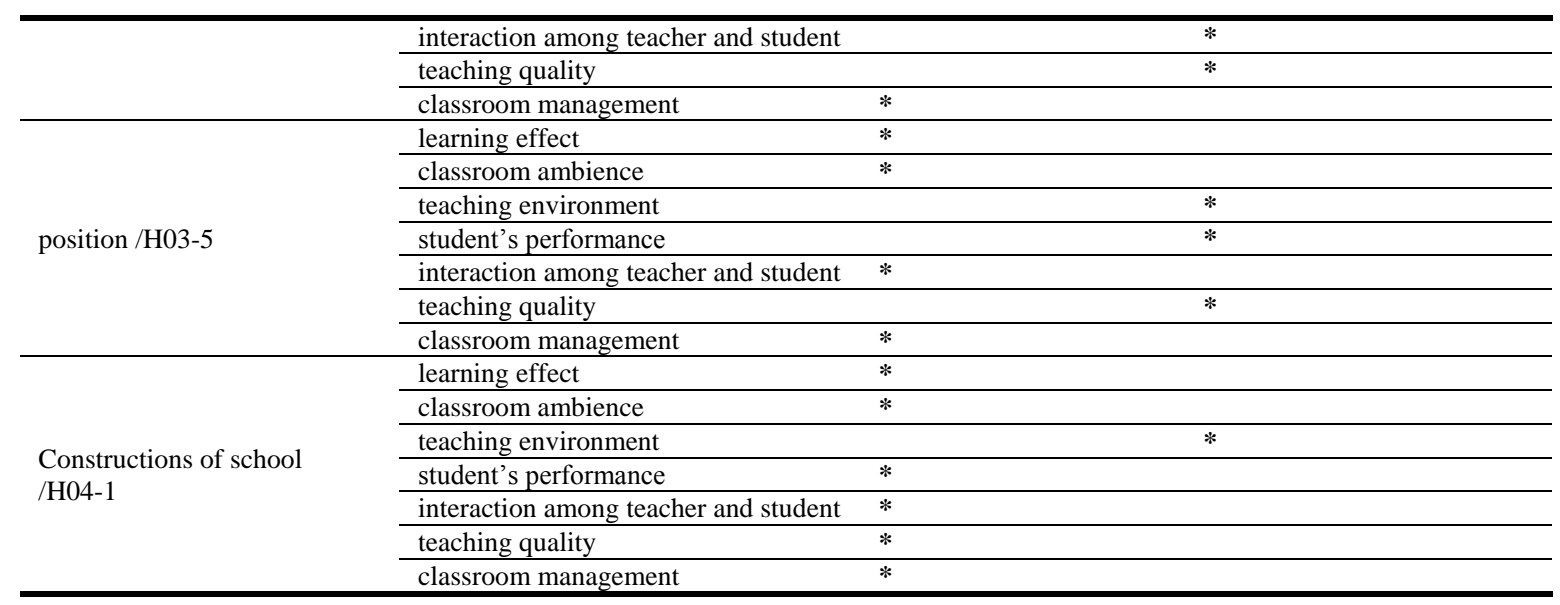

TABLE III: THE CONNECTION BETWEEN POSITIVE DISCIPLINE ATTITUDES AND CLASSROOM MANAGEMENT EFFECTIVENESS

Supporting right discipline emotional positive learning classroom teaching student's among teaching classroom system perception discipline emotional positive learning classroom teaching student's among teaching classroom
manageme-nt discipline effect ambience environme-nt performan-ce teacher and quality management

student

\begin{tabular}{|c|c|c|c|c|c|c|c|c|c|c|c|c|}
\hline \multicolumn{13}{|c|}{$\begin{array}{l}\text { Supporting } \\
\text { system }\end{array}$} \\
\hline & $0.59 * *$ & 1 & & & & & & & & & & \\
\hline $\begin{array}{l}\text { Supporting } \\
\text { system }\end{array}$ & $0.64 * *$ & $0.47 * *$ & 1 & & & & & & & & & \\
\hline $\begin{array}{l}\text { Supporting } \\
\text { system }\end{array}$ & $0.63 * *$ & $0.50 * *$ & $0.71 * *$ & 1 & & & & & & & & \\
\hline $\begin{array}{l}\text { Supporting } \\
\text { system }\end{array}$ & $0.85 * *$ & $0.78 * *$ & $0.85^{* *}$ & $0.85 * *$ & 1 & & & & & & & \\
\hline $\begin{array}{l}\text { Supporting } \\
\text { system }\end{array}$ & $0.58 * *$ & $0.44 * *$ & $0.62 * *$ & $0.56^{* *}$ & $0.66^{* *}$ & 1 & & & & & & \\
\hline $\begin{array}{l}\text { Supporting } \\
\text { system }\end{array}$ & $0.52 * *$ & $0.37 * *$ & $0.53 * *$ & $0.53 * *$ & $0.59 * *$ & $0.68 * *$ & 1 & & & & & \\
\hline $\begin{array}{l}\text { Supporting } \\
\text { system }\end{array}$ & $0.47 * *$ & $0.37 * *$ & $0.46^{* *}$ & $0.40 * *$ & $0.51 * *$ & $0.67 * *$ & $0.47 * *$ & 1 & & & & \\
\hline $\begin{array}{l}\text { Supporting } \\
\text { system }\end{array}$ & $0.58 * *$ & $0.40 * *$ & $0.47 * *$ & $0.40 * *$ & $0.55 * *$ & $0.61 * *$ & $0.44 * *$ & $0.70 * *$ & 1 & & & \\
\hline $\begin{array}{l}\text { Supporting } \\
\text { system }\end{array}$ & $0.59 * *$ & $0.43 * *$ & $0.54^{* *} *$ & $0.59 * *$ & $0.64 * *$ & $0.67 * *$ & $0.77 * *$ & $0.51 * *$ & $0.55 * *$ & 1 & & \\
\hline $\begin{array}{l}\text { Supporting } \\
\text { system }\end{array}$ & $0.55^{* *}$ & $0.45 * *$ & $0.52 * *$ & $0.46^{* *}$ & $0.60 * *$ & $0.65 * *$ & $0.46^{* *}$ & $0.52 * *$ & $0.55^{* *}$ & $0.51 * *$ & 1 & \\
\hline $\begin{array}{l}\text { Supporting } \\
\text { system }\end{array}$ & $0.68 * *$ & $0.51 * *$ & $0.65^{* *}$ & $0.61 * *$ & $0.73 * *$ & $0.88 * *$ & $0.80 * *$ & $0.80 * *$ & $0.78 * *$ & $0.83^{* *}$ & $0.75 * *$ & 1 \\
\hline
\end{tabular}

\section{The Relation between Positive Discipline Attitude and Class Management Effectiveness}

The analysis as shown in Table III, the study uses the Pearson's production-moment correlation to analyze the relation between positive discipline attitude and class management effectiveness. The result of correlation coefficient between 37 85, and each aspect and entire both are significance $(p<05)$, it means that junior high school teachers' attitudes of positive discipline significant impact class management effectiveness. When junior high school teachers in teaching and operating classes who use positive discipline to guide students in learning and complying with the code of ethic, it can be approved the class management effectiveness.

\section{CONCLUSIONS AND RECOMMENDATIONS}

\section{A. Conclusions}

1) Teachers who have master or doctoral degree and age 41 to 50 years old have better attitudes of positive discipline.
2) Teachers in junior high school who are under 30 , have to teach and in administrative positions, have less than five years seniorities, and have master or doctoral degree have better class management effectiveness.

3) Teachers who teach in remote junior high schools that students less 100 have better attitudes of positive discipline and class management effectiveness.

4) Teachers' better attitudes of positive discipline significant impact class management effectiveness.

\section{B. Recommendations}

There are two parts of recommendation.

1) For education authorities

To reduce student numbers in class and develop teaching and learning in small schools. To integrate educational resources of each school and inspect and learn from each other's work.

\section{2) For schools and teachers}

To promote teachers' specialties and experiences sharing. To encourage teachers are in-service education and lifelong learning. Encouraging teachers practice positive discipline to 
improve class management effectiveness

\section{The Follow-up Study}

\section{1) Study methods}

In this study, it uses the quantitative analysis to analyze data of questionnaires, and do conclusions and recommendations. Subjects may not honestly do questionnaires or misunderstanding topics, so the survey cannot get real ideas of subjects to do quantitative analysis. In future, the quality of survey can take into research. To collect more date to close the reality and compare with results of survey which can make a study more meaningful and valuable.

\section{2) Study targets}

The target of this study is limited to the central Taiwan which is junior high school teachers in Taichung City, Changhua County, and Nantou County. The inference of study restricts to the area. In future, the study can expand the area and targets to different stages of the school, in order to find out a wider, more level teachers' attitudes and perception of positive discipline impact class management effectiveness to make a more complete and representative study.

\section{REFERENCES}

[1] MOE. (2007). The precaution for school to set the note of teacher counsels and disciplines student. Law and Regulations Retrieving System. [Online]. Available: http://edu.law.moe.gov.tw/LawContent. aspx?id =GL000944

[2] S. H. Zhou, "The study in the relations between class management effectiveness and positive discipline of elementary school teachers in taipei county," Master's dissertation presented at NTUE at Taipei, Taiwan, 2009.

[3] J. L. Lai, "The relationship between positive discipline and classroom management implemented by elementary school teachers in pingtung county," Master's dissertation presented at MPUE at Pingtung, Taiwan 2010.

[4] Z. L. Ye, "The study in the relations between class management effectiveness and positive discipline of elementary school mentors in new taipei city," Master's dissertation presented at NTUE at Taipei, Taiwan, 2011.

[5] J. L. Lu, "The study in the relations between class management effectiveness and positive discipline of junior high school mentors in taoyuan county," Master's dissertation presented at FJU at Taipei, Taiwan, 2011.

[6] J. F. Zheng, "A case study in hsinchu area: the relations between class management effectiveness, classroom ambience and positive discipline," Master's dissertation presented at CYCU at Hsinchu, Taiwan, 2011.

[7] S. L. Liu and Q. W. Lin. "The Study of class management effectiveness and students' learning motivation in junior high school teachers," The Archive of Guidance \& Counseling, vol. 29, no. 1, pp. 25-46, 2007.

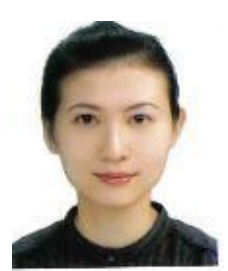

Chia-Ling Shih is a doctoral student of the Department of Industrial Education and Technology, National Changhua University of Education (NCUE), Taiwan and now she is a high school teacher in Taiwan, Taichung.

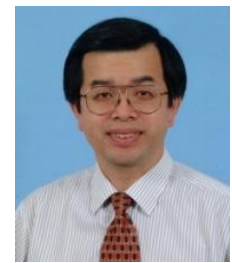

Chin-Chang Wu received M.S. in education from National Changhua University of Education, Taiwan, R.O.C. and $\mathrm{Ph} . \mathrm{D}$ in industrial education and Technology from National Changhua University of Education in 2005. He has been a school principal in Dong- Shing Elementary School, Taiwan, R.O.C. and dealt with administrative affairs of the school. His research interests include leading, technology, and vocational education.

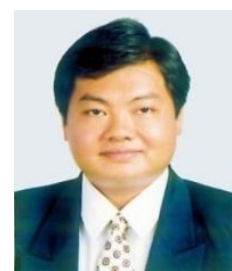

Fang-Pin Lai received M.S. degree at the Department of Industry Education from National Taiwan Normal University in 1994, and currently is a doctoral student of the Department of Industrial Education and Technology at National Changhua University of Education (NCUE), Taiwan, R.O.C.

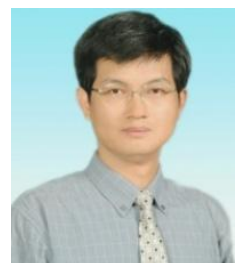

Chin-Wen Liao received both M.S. and Ph.D degrees in industrial education from National Taiwan Normal University, Taiwan, R.O.C. in 1994 and 2002, respectively. Since August 2011, he has been a professor in Department of Industrial Education and Technology at National Changhua University of Education (NCUE) in Taiwan, R.O.C. He teaches courses in technology and vocational education, energy education, course and teaching, organizational learning. His research interests include technology and vocational education, teacher education, energy education of technology, and learning organization. 